\title{
İşletmelerin COVID-19 pandemisi sürecindeki finansal performanslarının Entropi ve MAIRCA yöntemleri ile değerlendirilmesi: BIST gıda, içecek endeksi örneği
}

\author{
Evaluation of the financial performance of businesses during the \\ COVID-19 pandemic process with Entropy and MAIRCA methods: \\ BIST food, beverage index example
}

\author{
Ömer Kehribar ${ }^{1}$ \\ Ferhat Karademir ${ }^{2}$ iD \\ Samet Evci ${ }^{3}$
}

${ }^{1}$ Araştırma Görevlisi, Osmaniye Korkut Ata Üniversitesi, Osmaniye, Türkiye, omerkehribar@osmaniye.edu.tr

ORCID: 0000-0001-5555-6653

\begin{abstract}
2 Araştırma Görevlisi, Osmaniye Korkut Ata Üniversitesi, Osmaniye, Türkiye, ferhatkarademir@osmaniye.edu.tr

ORCID: 0000-0003-0599-4326
\end{abstract}

${ }^{3}$ Doçent Doktor, Osmaniye Korkut Ata Üniversitesi, Osmaniye, Türkiye, sametevci@osmaniye.edu.tr,

ORCID: 0000-0002-5854-3847

Sorumlu Yazar/Corresponding Author:

Ömer Kehribar

Osmaniye Korkut Ata Üniversitesi, Osmaniye, Türkiye, omerkehribar@osmaniye.edu.tr

Başvuru/Submitted: 14/01/2021

Revizyon/Revised: 1/02/2021

Kabul/Accepted: 8/02/2021

Yayın/Online Published: 25/03/2021

Attf/Citation: Kehribar, Ö., \& Karademir F., \& Evci, S., İşletmelerin COVID-19 pandemisi sürecindeki finansal performanslarının Entropi ve MAIRCA yöntemleri ile değerlendirilmesi: BIST gida, içecek endeksi örneği, bmij (2020) 9 (1): 200-214, doi:

https://doi.org/10.15295/bmij.v9i1.1748
Öz

COVID-19 pandemisinin beraberinde getirdiği kısıtlamalar sebebiyle temel ihtiyaçlara olan ilginin arttığı, bu sebeple de özellikle gıda işletmelerinin performans açısından etkilendiği düşünülmektedir. Bu çalışmada Borsa İstanbul Gida, İçecek (XGIDA) endeksinde bulunan işletmelerin pandemi dönemindeki finansal açıdan performansları değerlendirilmiştir. Literatürde pandemi sürecinde gıda işletmelerinde henüz performans analizine yönelik çalışmaların bulunmaması sebebiyle ilgili endeksin tercih edilmesinin önemli olduğu düşünülmektedir. Çalışmada kriter ağırlıklandırma hesaplayan Entropi ve alternatiflerin performansın sıralayan MAIRCA yöntemleri kullanılmıştır. Entropi yöntemine göre en önemli kriterin Nakit Oran, en az önemli olan kriterin Aktif Kârlılık Oranı olduğu tespit edilmiş̧ir. MAIRCA yöntemine göre en iyi performans gösteren işletmenin G7 (FRIGO), en kötü performans gösteren işletmenin ise G19 (TKURU) olduğu tespit edilmiştir.

Anahtar Kelimeler: COVID-19, Finansal Performans, MAIRCA

Jel Kodlar1: C44, G19, L25

\begin{abstract}
It is thought that due to the restrictions brought about by the COVID-19 pandemic, interest in basic needs has increased, and therefore, significantly, food businesses are affected by performance. In this study, the financial performances of the businesses registered in the Borsa Istanbul Food, Beverage (XGIDA) index were evaluated during the pandemic period. It is thought that it is essential to choose the relevant index since there are no studies for performance analysis in food businesses during the literature's pandemic process. The entropy that calculates criterion weighting and MAIRCA methods that rank the performance of alternatives were used in the study. According to the entropy method, it has been determined that the most crucial criterion is the Cash Ratio, and the least important one is the Asset Profitability Ratio. According to the MAIRCA method, it was determined that the best performing business was G7 (FRIGO), and the worst-performing business was G19 (TKURU).
\end{abstract}

Keywords: COVID-19, Financial Performance, MAIRCA

Jel Codes: C44, G19, L25 


\section{Extended Abstract}

\section{Evaluation of the financial performance of businesses during the covid-19 pandemic process with Entropy and MAIRCA methods: BIST food, beverage index example}

\section{Literature}

When the literature is examined, many studies test financial performance on a business or sector basis with various methods. To give a few examples; Feng and Wang (2000), Yurdakul and İç (2003), Ertuğrul and Karakaşoğlu (2009) and Işık (2019) measure financial performance using the TOBSIS method in their studies. Ulutaş (2018), Orçun (2019), Şahin and Sarı (2019), Ayçin and Güçlü (2020) measured financial performance using various methods such as Entropy, MAIRCA and EDAS.

\section{Research subject}

This study aims to measure the performance of businesses using multi-criteria decision-making methods (MCDM).

\section{Research purpose and importance}

The purpose of this study is to measure the financial performance of the businesses in the food and beverage index in Borsa Istanbul during the COVID-19 pandemic period, using Entropy and MAIRCA methods. Since there are no publications in the literature that measure the performance of businesses in the food sector, especially during the pandemic period, it can be stated that it is vital to research this area.

\section{Contribution of the article to the literature}

Since there are few studies in the literature on financial performance analysis using the MAIRCA method, it is believed that the contribution of the study to the literature is essential. It can also be said that the study contributes to the literature in terms of dealing with the pandemic period as a data set.

\section{Design and method}

Entropy and MAIRCA are used as methods in this study. The entropy method was used to calculate the weights of the criteria in the decision problem. MAIRCA method has been used to rank the businesses according to their performance in the relevant financial criteria.

\section{Research type}

In the study, an applied method was chosen to investigate the performances of businesses registered in the BIST food and beverage index. In line with the information obtained from the application, businesses are listed according to their performance.

\section{Research problems}

It was declared a pandemic by the World Health Organization (WHO) on 11.03.2020, and with the announcement of a pandemic, it has become necessary to make crucial decisions in the economy and business life. It is believed that such decisions significantly affect the performance of the countries at the macro level and the enterprises at the micro-level. It is thought that significantly the increase in demand for basic needs impacts the financial performance of businesses operating in the food sector. This situation creates the problem of the study and determines the purpose of the study.

\section{Data collection method}

This study covers the data of 23 companies included in the BIST Food, Beverage index between 11.03 .2020 (which has been declared a pandemic in the world) and 31.12.2020. The data were obtained from the KAP (public disclosure platform) and Finnet platforms.

\section{Quantitative analysis}

Within the study's scope, a quantitative research method that enables the analysis of numerical data was used. Quantitative data is defined as the value of data in counts or numbers where each data-set has a unique numerical value associated with it. This data is any quantifiable information that can be used for mathematical calculations and statistical analysis.

\section{Research model}

The multi-criteria decision-making method (MCDM) was used in the study. MCDM is a sub-discipline of operations research that explicitly evaluates multiple conflicting criteria in decision making (both in daily life and in settings such as business, government and medicine).

\section{Findings and discussion}

At the beginning of the analysis, the most crucial criterion among the financial criteria was the Cash Ratio. This is assumed to be a natural consequence of the increase in cash inflows to businesses due to increased essential food spending by consumers during the pandemic process. After determining the essential criteria, as a result of the analysis, the best performing alternative was found as Frigo-Pak Food Industry and Trade Inc. This firm has undoubtedly been the best performing company during the pandemic process, as it managed the cash flow best.

\section{Findings as a result of the analysis}

When looking at the results of entropy values and criterion weights $\left(w_{j}\right)$, it is seen that the most important financial performance indicator is the Cash Ratio $\left(w_{j}=0.3584\right)$ and the least important indicator is the Return on Asset (ROA) Ratio $\left(w_{j}=0.0427\right)$. After finding the criterion weights with the entropy method, the alternatives were listed with the MAIRCA method. Accordingly, 
during the COVID-19 pandemic, it has been determined that the three alternatives with the best financial performance are respectively G7 (FRIGO) with $Q_{i}=0.0090$ final criterion function value, G4 (CCOLA) with $Q_{i}=0.0137$ final criterion function value and G6 (FADE) with $Q_{i}=0.0165$ final criteria function value. The three alternatives with the worst financial performance are respectively G16 (PINSU) with $Q_{i}=0.0340$ final criterion function value, G12 (MERKO) with $Q_{i}=0.0344$ final criterion function value, and G19 (TKURU) with $Q_{i}=0.0365$.

\section{Discussing the findings with the literature}

In this study, it was determined that the most important criterion for companies is the Cash Ratio. This result was similar to Ayçin and Güçlü (2020). Since no studies based on the food sector have been found, new studies are needed to compare businesses' financial performance.

\section{Conclusion, recommendation and limitations}

The best performing company in the study is Frigo-Pak Food Industry and Trade Inc., and the worst-performing company is Taze\&Kuru Food Inc. Although the COVID-19 pandemic process has been discussed in the study, it can be determined in what direction the criteria differ and how the alternatives have changed by considering them as before and after the pandemic in future studies. Besides, in future studies, the food index and other BIST indices can be examined by different methods and periods. The limitation of this study is that the data set is challenging to obtain. Another limitation, especially in terms of the fee to obtain financial ratios belonging to companies, is the financial limitation.

\section{Results of the article}

According to the results of multi-criteria decision-making methods, the most critical financial criterion for companies in the food industry during the covid-19 pandemic process, the Cash Ratio, was found. After criterion weighting, the best performing firms were identified as G7, G4 and G6.

\section{Suggestions based on results}

Although the COVID-19 pandemic process has been discussed in this study, it can be determined in what direction the criteria differ and how the alternatives have changed by considering them as before and after the pandemic in future studies. In future studies, the food index and other BIST indices can be examined by different methods and periods.

\section{Limitations of the article}

While examining the businesses' performances during the pandemic process, the data set of the study was limited based on the food sector. 


\section{Giriş}

Yeni tip korona virüs ilk olarak Çin'in Hubei eyaletine bağlı Wuhan şehrinde ortaya çıkmış ve kısa sürede tüm dünyayı etkisi altına almıştır. Hızla yayılan COVID-19 salgını tüm canlıların hayatını etkilemiş, günlük rutinlerden iş hayatına, devlet yönetiminden küresel kararlara kadar birçok alanda etkisini göstermiştir. Ardından 11.03.2020 tarihinde Dünya Sağlık Örgütü (WHO) tarafından pandemi olarak ilan edilmiştir. Pandemi ilan edilmesiyle birlikte, ekonomi ve iş hayatında önemli kararların alınması zorunlu hale gelmiştir. Bu gibi kararlar makro düzeyde ülkelerin mikro düzeyde ise işletmelerin performanslarını önemli ölçüde etkilediğine inanılmaktadır. Özellikle temel ihtiyaçlara olan talep artışının gıda sektöründe faaliyet gösteren işletmelerin finansal performanslarına etki ettiği düşünülmektedir. Çalışmanın yapıldığı süreçte literatürde, özellikle pandemi döneminde gıda sektöründeki işletmelerin performansını ölçen yayınlar bulunmadığından bu alanda araştırma yapılmasının önemli olduğu ifade edilebilir.

İşletmelerin nakit, fon gibi kaynaklarını ne ölçüde etkin kullandığını ifade eden finansal performans, işletmelerin performansını değerlendirirken kullanılan önemli göstergelerden biridir. Finansal performans ölçülürken tek bir kriterden faydalanmak mümkün olamaz. İçerisinde farklı kriterleri barındıran birçok ölçüt bulunmaktadır. Bu açıdan ele alındığında, işletmelerin finansal performanslarını ölçerken çok kriterli karar verme yöntemleri (ÇKKV) rahatlıkla ve sıkça kullanılabilmektedir (Ayçin ve Güçlü, 2020: 288). Özellikle olağanüstü durumlar göz önünde bulundurulduğunda finansal performansın ölçülmesi ve değerlendirilmesi, işletmeler açısından son derece önemli hale gelmiştir.

Çalışmada Entropi ve MAIRCA (Çok Nitelikli İdeal-Gerçek Karşılaştırmalı Analiz) yöntemleri kullanılarak BIST Gıda, İçecek endeksinde yer alan işletmelerin COVID-19 sürecindeki finansal performansları değerlendirilmiştir. İlk olarak finansal performans göstergelerinin tespit edilmesi amacıyla literatür taraması yapılmıştır. Literatür incelendiğinde finansal performans ölçütleri olarak hisse başına kâr oranı, cari oran, nakit oran, aktif devir hızı oranı, stok devir hızı oranı, alacak devir hızı oranı, finansal kaldıraç oranı ve aktif kârlılık oranı gibi göstergelerin sıkça kullanıldığı tespit edilmiştir. Çalışmada kullanılan finansal performans kriterlerinin ağırlıkları Entropi metoduyla hesaplanmıştır. Objektif kriter ağırlıklandırma yöntemlerinden olan Entropinin tercih edilesinin sebebi, herhangi bir öznel görüşe ihtiyaç duyulmadan performans kriterleri ile değerlendirme yapılabilmesidir. Kriter ağırlıkları hesaplandıktan sonra MAIRCA yöntemiyle performans değerleri ve sıralamaları tespit edilmiştir. MAIRCA yöntemi kullanılarak finansal performans analizine yönelik literatürde az sayıda çalışma olması sebebiyle çalışmanın literatüre katkısının önemli olduğuna inanılmaktadır. Uygulama kısmından sonra sonuçlara yer verilerek çalışma tamamlanmıştır.

\section{Literatür incelemesi}

Literatür incelendiğinde, finansal performansı işletme ya da sektör bazında çeşitli yöntemlerle test eden birçok ulusal ve uluslararası çalışma bulunmaktadır. Bu çalışmalar özetlenecek olursa; Feng ve Wang (2000) havayolu şirketlerinin finansal performansını ölçmek için TOPSIS yöntemiyle borç devir hızı, likidite ve kârlılık oranı gibi çeşitli finansal oranları kullanarak incelemiş ve sadece finansal oranların kullanılması havayolu şirketlerinin performans değerlendirmesinde tek başına yeterli olmayacağını vurgulamışlardır. Yurdakul ve İç (2003) otomotiv firmaları üzerinde TOPSIS yöntemini kullanarak yaptı̆̆ çalışmada pay senetleri ile finansal performans göstergeleri arasında tutarlı bir ilişki olduğunu tespit etmişlerdir. Ho ve Wu (2006) çalışmalarında bankaların kârlılık, kaldıraç ve likidite oranları gibi finansal göstergelerini Gri İlişkisel Analiz yöntemi ile incelemiş ve hisse getirisi ve kârlılı̆̆ın en önemli performans ölçütleri olduğunu tespit etmişlerdir. Ertuğrul ve Karakaşoğlu (2009) çalışmalarında Borsa İstanbul'da yer alan çimento işletmelerinin finansal performanslarını faaliyet oranları, kârlılık ve büyüme ile likidite oranları gibi göstergeleri Bulanık AHP ve TOPSIS kullanarak hesaplamış ve en iyi performans gösteren firmanın Adana Çimento olduğunu tespit etmişlerdir. Tseng, Chiu ve Chen (2009) Tayvan'da faaliyet gösteren TFT-LCD panel üreticileri üzerinde yaptıkları çalışmalarında, işletmeler için en önemli kriterlerin rekabet edilebilirlik performansı ve finansal performans olduğunu DEA, TOSIS ve AHP yöntemleri ile tespit etmişlerdir. Bayrakdaroğlu ve Yalçın (2012) çalışmalarında BIST 30 endeksinde yer alan 17 imalat işletmesi için çeşitli finansal performans kriterlerini Bulanık AHP ve VIKOR yöntemlerini kullanarak incelemiş ve en başarılı işletmenin Doğan Yayın Holding olduğunu, en az başarılı firmanın ise Ereğli Demir ve Çelik Fabrikaları T.A.Ş. olduğunu belirlemişlerdir. Lee, Lin ve Shin (2012) çalışmalarında etkinlik, finansal kaldıraç, yatırım geri dönüşü gibi çeşitli finansal oranlar ile Kore ve Tayvan'da faaliyet gösteren deniz taşımacılığı firmalarına Entropi ve Gri İlişkisel Analiz yöntemleri ile performans analizi yapmış ve 1999-2007 yılları arasında Tayvanlı şirketlerin Koreli 
şirketlere kıyasla daha iyi performans göstermiş olduğu sonucuna varmışlardır. Ömürbek, Karaatlı ve Balc1 (2016) Entropi, MAUT ve SAW yöntemlerini kullanarak Borsa İstanbul'da işlem gören 6 otomotiv firmasının finansal performanslarını çeşitli finansal göstergeler ile incelemiş ve en iyi performans gösteren firmanın C firması olduğunu belirlemişlerdir. Ulutaş (2018) 7 lojistik firmasına Entropi ve EDAS yöntemleri ile Net Satıs, Faiz ve Vergi Öncesi Kâr, Aktif Toplam ve Çalışan sayısı gibi birçok kriteri kullanarak performans analizi gerçekleştirmiş ve sonuç olarak en iyi finansal performansa sahip olan firmanın Mars Lojistik A.Ş. olduğunu belirlemiştir. Ayçin (2018) Menkul Kıymet Yatırım Ortaklığ1 (MKYO) Endeksinde bulunan 8 işletme için Entropi ve Gri İlişkisel Analiz yöntemleri ile Öz Kârlılık Oranı, Piyasa Katma Değeri (MVA), Öz Sermaye Kârlılık Oranı (ROE), Piyasa Değeri / Defter Değeri, Beta Endeksi ve Fiyat Kazanç oranı kriterlerini kullanarak analiz etmiş ve en başarılı firmanın İş Yatırım Ortaklığı ve en az başarılı işletmenin ise Garanti Yatırım Ortaklığı olduğunu tespit etmiştir. Anthony, Behnoee, Hassanpour ve Pamucar (2019) Hindistan'da bulunan kimya işletmeleri üzerine Entropi, VZA, COPRAS ve TOPSIS yöntemleri ile finansal performans değerlendirmesi yapmış ve Entropiye göre en önemli kriterin asit-test oranı olduğu, VZA, COPRAS ve TOPSIS yöntemlerine göre ise kriter finansal göstergelerin yıllara göre farklılaştığını tespit etmişlerdir. Işık (2019) çalışmasında BIST 30 endeksinde yer alan 15 işletmenin finansal performanslarını Entropi ve TOPSIS yöntemi ile değerlendirmiş ve Entropi yöntemine göre en önemli kriterin asit-test oranı olduğu ve en iyi performansa sahip işletmenin Koza Altın, en kötü performansa sahip olan işletmenin ise Kardemir (D) işletmesinin olduğu sonucuna varmıştır. Orçun (2019) Entropi ve WASPAS yöntemlerini kullanarak enerji sektöründe faaliyet gösteren 5 işletme için finansal performans değerlendirmesi yapmış ve bu sektörde faaliyet gösteren işletmeleri için en önemli kriterin Entropi yöntemine göre aktif kârlılık olduğu belirlemiş ve en iyi performans gösteren firmanın ise WASPAS yöntemine göre Ayen Enerji işletmesinin olduğunu tespit etmiştir. Şahin ve Sarı (2019) çalışmasında imalat sektöründe faaliyet gösteren 27 işletme için finansal performans incelemiştir. Entropi, VIKOR ve TOPSIS yöntemlerinin kullanıldığı çalışmada en önemli kriterin 2013 ve 2016 yılları için aktif devir hızı bulunurken 2014 ve 2015 yılları için ise en önemli kriterin cari oran bulunmuştur. VIKOR ve TOPSİS yöntemlerine göre ise en iyi finansal performans gösteren işletmelerin Goodyear, Türk Traktör ve Konya Çimento işletmelerinin olduğu sonucuna varılmıştır. Çanakçığlu (2019) XKMYA endeksinde yer alan 30 işletme için finansal performansı Entropi, Borda Sayım ve Gri İlişkisel Analiz yöntemleri ile incelemiştir. Analize dahil edilen işletmeler için en önemli kriterin alacak devir hızı olduğu tespit edilmiştir. Finansal başarı olarak değerlendirildiğinde en iyi performans gösteren işletmenin Sanifoam Sünger Sanayi ve Ticaret Anonim Şirketi, en az başarılı olan işletme ise Aygaz Anonim Şirketi olmuştur. Ayçin ve Güçlü (2020) çalışmalarında BIST ticaret endeksinde yer alan işletmelerin finansal performanslarını Entropi ve MAIRCA yöntemleri ile test etmişlerdir. Entropi yöntemi ile kriter olarak kullanılan finansal oranlar arasında en önemli kriterlerin asit-test oranı, aktif devir hızı ve nakit oranı olduğu tespit edilmiştir. MAIRCA yöntemi ile ilgili işletmeler finansal performanslarına göre sıralanmış ve en iyi performans gösteren işletmelerin sırasıyla Milpa Ticari ve Sınai Ürünler Pazarlama Sanayi ve Ticaret Anonim Şirketi, Sanko Pazarlama İthalat İhracat Anonim Şirketi ve Teknosa İç ve Dış Ticaret Anonim Şirketi olduğu tespit edilmiştir. Çalış ve Sakarya (2020) çalışmalarında BİST Bankacılık Endeksi'nde faaliyet gösteren bankaların hisse senedi getirileri ile finansal performans arasındaki ilişki incelemişlerdir. 2017 yılı itibariyle işlem görmekte olan 12 bankanın 2015 - 2017 yılları arasındaki verilerinden yararlanılarak analiz yapılmıştır. PROMETHEE yönteminin kullanıldığı analiz sonuçlarına göre finansal performans açısından en başarılı bankanın Akbank, ikinci olarak ise Garanti bankasının başarılı bir grafik çizdiği görülmüştür. Tetik ve Şahin (2020) çalışmalarında 2011-2019 yıllarında faaliyet gösteren yedi katılım bankasının finansal performanslarını TOPSIS yöntemi ile incelemişlerdir. Yapılan analizler sonucunda katılım bankaları arasında en yüksek finansal performansa sahip olan banka Türkiye Finans Katılım Bankası olmuştur. İkinci sırada Albaraka Türk Katılım Bankası ve üçüncü sırada ise Kuveyt Türk Katılım bankası yer almıştır. Ersoy (2020) çalışmasında Borsa İstanbul (BIST) Ulaştırma endeksinde (XULAS) işlem gören 8 firmanın finansal performansını Gri İlişkisel Analiz (GİA) yöntemi kullanılarak ölçmüş̧ür. Çalışma sonucunda, GİA değerlerinin çok yüksek sapmalar göstermediği ve yüksek kârlılığa sahip işletmelerin üst sıralarda yer aldığı tespit edilmiştir.

\section{Amaç, kapsam ve yöntem}

\section{Çalışmanın amacı}

Bu çalışmanın amacı Borsa İstanbul'da yer alan gıda, içecek endeksinde yer alan işletmelerin COVID19 pandemi döneminde gösterdikleri finansal performansın çeşitli kriterler ile ölçülmesidir. 


\section{Çalışmanın kapsamı}

Bu çalışma BIST Gıda, İçecek endeksinde yer alan 23 şirketin dünyada pandemi ilan edilen 11.03.2020 tarihi ile 31.12.2020 tarihi arasındaki verilerini kapsamaktadır. Veriler KAP ve Finnet platformlarından temin edilmiştir. Söz konusu işletmelerin "Hisse Başına Kâr Oranı, Cari Oranı, Stok Devir Hızı, Aktif Kârlılık Oranı, Nakit Oranı, Finansal Kaldıraç Oranı, Aktif Devir Hızı ve Alacak Devir Hızı" finansal performans kriteri olarak belirlenmiştir. Literatür incelendiğinde finansal performans kriterleri olarak sıklıkla kullanıldığı tespit edilen bu oranlar tercih edilmiştir (Ho ve Wu, 2006; Ertuğrul ve Karakaşoğlu, 2009; Ayçin ve Güçlü, 2020).

Tablo 1: BIST Gıda, İçecek Endeksinde Bulunan İşletmeler

\begin{tabular}{ccc|ccc}
\hline BIST Kodu & Tablo Kodu & İşletme Adı & BIST Kodu & Tablo Kodu & İşletme Adı \\
\hline AEFES & G1 & Anadolu Efes & OYLUM & G13 & Oylum Sınai Yatırımlar \\
\hline AVOD & G2 & A.V.O.D. Gıda ve Tarım & PENGD & G14 & Penguen Gıda \\
\hline BANVT & G3 & Banvit & PETUN & G15 & Pınar Et ve Un \\
\hline CCOLA & G4 & Coca Cola İçecek & PINSU & G16 & Pınar Su \\
\hline ERSU & G5 & Ersu G1da & PNSUT & G17 & Pınar Süt \\
\hline FADE & G6 & Fade Gıda & TATGD & G18 & Tat Gıda \\
\hline FRIGO & G7 & Frigo Pak G1da & TKURU & G19 & Taze Kuru G1da \\
\hline KERVT & G8 & Kerevitaş G1da & TUKAS & G20 & Tukaş \\
\hline KRVGD & G9 & Kervan G1da & ULUUN & G21 & Ulusoy Un Sanayi \\
\hline KNFRT & G10 & Konfrut G1da & ULKER & G22 & Ülker Bisküvi \\
\hline KRSTL & G11 & Kristal Cola & VANGD & G23 & Vanet Gıda \\
\hline MERKO & G12 & Merko G1da & & & \\
\hline Kayk: & & & &
\end{tabular}

Kaynak: https://www.kap.org.tr/tr/Endeksler

\section{Çalışmanın yöntemi}

Bu çalışmada yöntem olarak Entropi ve MAIRCA kullanılmıştır. Entropi yöntemi karar probleminde bulunan kriterlerin ağılıklarının hesaplanması için kullanılmıştır. MAIRCA yöntemi ise işletmelerin ilgili finansal kriterlerdeki performanslarına göre sıralanmasında kullanılmıştır. Bu çalışma, "Etik Kurul İzni gerektiren" bir çalışma olmadığı için Etik Kurul İzin Belgesi alınmamıştır.

\section{Entropi yöntemi}

Bu yöntemde beş aşama bulunmaktadır. Söz konusu bu aşamalar aşağıda sırasıyla açıklanmıştır (Wang ve Lee, 2009:8982).

İlk aşamada karar matrisi oluşturulmaktadır. $x_{i j}$ değerlerinden oluşan $D$ matrisi aşağıdaki eşitlik (1)'de gösterilmektedir:

$$
D=\begin{gathered}
A_{1} \\
A_{2} \\
\vdots \\
A_{m}
\end{gathered}\left[\begin{array}{cccc}
x_{11} & x_{12} & \cdots & x_{1 n} \\
x_{21} & x_{22} & \cdots & x_{2 n} \\
\vdots & \vdots & \vdots & \vdots \\
x_{m 1} & x_{m 2} & \cdots & x_{m m}
\end{array}\right]
$$

Yukarıdaki karar matrisinde bulunan $x_{i j}$ değerleri, $i$ alternatifinin $j$ değerlendirme kriterine göre aldığı değeri ifade etmektedir (Li, Wang, Liu, Xin, Yang ve Gao, 2011:2807). Karar alternatif sayısı $m$ ile değerlendirme kriter sayısı ise $n$ ile gösterilmektedir. Karar matrisi oluşturulurken sıfır veya negatif değerlerin bulunmamasına dikkat edilmelidir. Matriste böyle değer veya değerler var ise Z-skoru standartlaştırma dönüşümü ile ilgili değerler pozitife dönüştürülmelidir. Z-skoru aşağıdaki formül ile hesaplanmaktadır. 
$z_{i j}=\frac{x_{i j}-\bar{X}_{j}}{\sigma_{j}}$

Eşitlik (3)'te ifade edilen dönüşüm ile karar matrisindeki değerler pozitife dönüştürülür.

$z_{i j}^{\prime}=z_{i j}+C \quad C>\left|\min z_{i j}\right|$

İkinci aşamada karar matrisine normalizasyon işlemi yapılmaktadır. Alternatiflere ait değerlendirme kriterleri bu işlem ile [0,1] değer aralığında standart hale getirilecektir. Bu işlemin formülize hali eşitlik (4)'de verilmiştir.

$p_{i j}=\frac{x_{i j}}{\sum_{i=1}^{m} x_{i j}}$

Eşitlik (4)'de bulunan $i$ alternatifinin $j$ değerlendirme kriterine göre aldığı normalize değerler $p_{i j}$ olarak gösterilmektir.

Üçüncü aşamada kriterlere ait Entropi değerleri hesaplanmaktadır. Değerlendirme kriterlerine ait Entropi değerleri $e_{j}$ olarak tanımlanmaktadır ve eşitlik (5)'teki formül ile hesaplanmaktadır.

$e_{j}=-k \cdot \sum_{j=1}^{n} p_{i j} \cdot \ln \left(p_{i j}\right)$

Eşitlik (5)'te yer alan $e_{j}$ değeri 0 ile 1 arasında değer alır. Sabit bir katsayı olan $k$ değeri ise $k=(\ln (m))^{-1}$ formülü ile hesaplanır.

Dördüncü aşamada kriterlere ait farklılaşma dereceleri hesaplanmaktadır. Burada eşitlik (5)'te bulunan Entropi $\left(e_{j}\right)$ değerlerinden yararlanılarak farklılaşma dereceleri olan $d_{j}$ değerleri tüm kriterler için aşağıdaki eşitlik (6)'teki formül ile hesaplanmaktadır.

$d_{j}=1-e_{j}$

Beşinci ve son aşamada Entropi kriter ağırlıkları, her kritere ait farklılaşma derecesinin toplam farklılaşma derecesine bölünmesi ile elde edilmektedir. Ağırlık değerlerine $\left(w_{j}\right)$ ait eşitlik aşağıda gösterilmektedir.

$w_{j}=\frac{d_{j}}{\sum_{j=1}^{n} d_{j}}$

\section{MAIRCA yöntemi}

Literatürde ilk olarak Gigović, Pamučar, Bajić ve Milićević (2016) tarafından kullanılan MAIRCA yöntemi ÇKKV yöntemidir. Bu yöntemin mantığı, ampirik ve ideal derecelendirmeler arasındaki boşlukları anlamlandırma şeklindedir. Karar alternatiflerinin toplam boşluklarını elde etmek için her kriterin boşlukları toplanmaktadır. Uygulama neticesinde alternatifler arasından en az boşluk değerine sahip seçeneğin ilk sırayı aldığı görülecektir (Gigović vd., 2016:11; Ayçin ve Güçlü, 2020:296).

MAIRCA yöntemi süreci sekiz aşamadan meydana gelmektedir (Pamucar, Tarle ve Parezanovic 2018:1646-1648):

İlk aşamada her bir alternatifin $\left(A_{i}\right)$ kriter değerlerinin $C_{j}$ yer aldığı başlangıç karar matrisi oluşturulmaktadır. Karar matrisi aşağıdaki eşitlik (8)'de gösterilmektedir.

$X=\left[\begin{array}{cccc}C_{1} & C_{2} & \ldots & C_{n} \\ x_{11} & x_{12} & \cdots & x_{1 n} \\ x_{21} & x_{22} & \cdots & x_{2 n} \\ \vdots & \vdots & \ddots & \vdots \\ x_{m 1} & x_{m 2} & \cdots & x_{m n}\end{array}\right]$

Yukarıda yer alan $\mathrm{X}$ matrisindeki kriterler nicel olmasının yanında nitel değerler de alabilir. Alternatifler içinden nitel kriterlerin aldığ değerler nicel kriterlerden farklı olarak karar vericilerin öncelikleri ile belirlenmektedir. 
İkinci aşamada alternatiflere ait öncelikler belirlenmektedir. Alternatiflerin sayısı $m$ ve $i^{\prime}$ ninci alternatifin önceliği $P_{A i}$ aşağıda yer alan eşitlik (9)'daki gibi hesaplanır.

$P_{A i}=\frac{1}{m} ; \sum_{i=1}^{m} P_{A i}=1 \quad i=1,2, \ldots, m$

Karar verici açısından tüm alternatiflere olan mesafe eşittir. Bundan dolayı tüm öncelikler aşağıdaki eşitlik (10)' da olduğu gibi eşit olacaktır.

$P_{A 1}=P_{A 2}=\cdots=P_{A m}$

Üçüncü aşamada teorik derecelendirme matrisi olan $\left(T_{p}\right)$ matrisi oluşturulmaktadır. Derecelendirme matrisi $\mathrm{m} \times \mathrm{n}$ boyutlu olacaktır ve $\mathrm{n}$ toplam kriter sayısını, $\mathrm{m}$ ise toplam alternatif sayısını ifade etmektedir. Matris eşitlik (11) yardımı ile aşağıdaki gibi $t_{p i j}$ matris elemanları, $P_{A i}$ alternatif öncelikleri ile kriter ağırlıkları olan $w_{j}$ çarpılarak elde edilmektedir.

$T_{p}=\left[\begin{array}{cccc}w_{1} & w_{2} & \ldots & w_{n} \\ t_{p 11} & t_{p 12} & \cdots & t_{p 1 n} \\ t_{p 21} & t_{p 22} & \ldots & t_{p 2 n} \\ \vdots & \vdots & \ddots & \vdots \\ t_{p m 1} & t_{p m 2} & \ldots & t_{p m n}\end{array}\right] \quad\left[\begin{array}{ccccc}P_{A 1} \cdot w_{1} & P_{A 1} \cdot w_{2} & \ldots & P_{A 1} \cdot w_{n} \\ P_{A 2} \cdot w_{1} & P_{A 2} \cdot w_{2} & \ldots & P_{A 2} \cdot w_{n} \\ \vdots & \vdots & \ddots & \vdots \\ P_{A m} \cdot w_{1} & P_{A m} \cdot w_{2} & \ldots & P_{A m} \cdot w_{n}\end{array}\right]$

Dördüncü aşamada gerçek derecelendirme matrisi olan $T_{r}$ matrisi tanımlanmaktadır. Bu matrise ait elemanlar eşitlik (12)'de gösterilmektedir.

$T_{r}=\left[\begin{array}{cccc}C_{1} & C_{2} & \cdots & C_{n} \\ t_{r 11} & t_{r 12} & \cdots & t_{r 1 n} \\ t_{r 21} & t_{r 22} & \cdots & t_{r 2 n} \\ \vdots & \vdots & \ddots & \vdots \\ t_{r m 1} & t_{r m 2} & \cdots & t_{r m n}\end{array}\right]$

Gerçek derecelendirme $\left(T_{r}\right)$ matrisinin hesaplanabilmesi için başlangıç karar matrisi olan $X$ ve teorik derecelendirme matrisi olan $\left(T_{p}\right)^{\prime}$ den yararlanılır. Maliyet yönlü kriter hesaplaması için eşitlik (13), kazanç yönlü hesaplama için ise eşitlik (14)'ten faydalanılır.

$$
\begin{aligned}
& T_{r i j}=T_{p i j} \cdot\left(\frac{x_{i j}-x_{i j}^{+}}{x_{i j}^{-}+x_{i j}^{+}}\right) \\
& T_{r i j}=T_{p i j} \cdot\left(\frac{x_{i j}-x_{i j}^{-}}{x_{i j}^{+}+x_{i j}^{\bar{j}}}\right)
\end{aligned}
$$

Eşitlik (13) ve (14)'te bulunan $x_{i j}^{+}$kriterinin alternatiften aldığı en yüksek değeri $\left(x_{i j}^{+}=\right.$ $\left.\max \left(x_{1}, x_{2}, \ldots, x_{m}\right)\right), x_{i j}^{-}$ise kriterin alternatiften aldığı en düşük değeri $\left(x_{i j}^{+}=\min \left(x_{1}, x_{2}, \ldots, x_{m}\right)\right)$, $x_{i j}^{-}$temsil etmektedir.

Beşinci aşamada toplam boşluk matrisi olan $(G)$ matrisi hesaplanmaktadır. Bu matris teorik $\left(T_{p}\right)$ ve gerçek $\left(T_{r}\right)$ derecelendirme matrislerinin farkına eşit olmakta ve aşağıdaki gibi hesaplanmaktadır.

$G=T_{p}-T_{r}=\left[\begin{array}{cccc}g_{11} & g_{12} & \cdots & g_{1 n} \\ g_{21} & g_{22} & \cdots & g_{2 n} \\ \vdots & \vdots & \ddots & \vdots \\ g_{m 1} & g_{m 2} & \cdots & g_{m n}\end{array}\right]$

$g_{i j}=t_{p i j}-t_{r i j} g_{i j} \in[0, \infty)$

Altıncı aşamada toplam boşluk alternatifler ile tanımlanmaktadır. Bir kriter için $\left(C_{j}\right)$ eğer bir alternatifin $\left(A_{i}\right)$ gerçek derecesi $\left(t_{r i j}\right)$ ile teorik derecesi $\left(t_{p i j}\right)$ sıfırdan farklı ve eşit ise boşluk matrisi değeri sıfır olacaktır $\left(g_{i j}=0\right)$. Böylece $C_{j}$ kriteri için $A_{i}$ alternatifi en ideal $\left(A_{i}^{+}\right)$alternatif olacaktır. Eğer bir alternatifin $\left(A_{i}\right)$ gerçek derecesi $\left(t_{r i j}\right)$ ile teorik derecesi $\left(t_{p i j}\right)$ sıfır ise $C_{j}$ kriteri için $A_{i}$ alternatifi en kötü $\left(A_{i}^{-}\right)$alternatif olacaktır. 
Yedinci aşamada alternatifler için nihai kriter fonksiyonları olan $Q_{i}$ fonksiyonu hesaplanmaktadır. Bu fonksiyonlar hesaplanırken tüm alternatifler için ayrı ayrı boşluk matrisinin $(G)$ satırları toplanmaktadır. Aşağıdaki şekilde hesaplanmaktadır.

$Q_{i}=\sum_{j=1}^{n} g_{i j}, \quad i=1,2, \ldots, m$

Sekizinci ve son aşamada ise en iyi alternatif seçilmektedir. Alternatiflere ait nihai kriter fonksiyonları sıralanırlar. En düşük değer alan alternatif en iyi alternatif olarak değerlendirilir.

\section{Bulgular}

Çalışmada BIST Gıda, İçecek Endeksinde (XGIDA) bulunan işletmelerin COVID-19 Pandemisi dönemindeki finansal performansları Entropi ve MAIRCA yöntemleri ile değerlendirilmiştir. Tablo 1'de verilen endekslere ilişkin performans kriter kısaltmaları ve adları Tablo 2' de gösterilmiştir.

Tablo 2. Finansal Performans Kriterleri

\begin{tabular}{cc}
\hline HBK & Hisse Başına Kâr Oranı \\
\hline CO & Cari Oran \\
\hline NO & Nakit Oran \\
\hline AkDH & Aktif Devir Hızı Oranı \\
\hline SDH & Stok Devir Hızı Oranı \\
\hline ADH & Alacak Devir Hızı Oranı \\
\hline FKO & Finansal Kaldıraç Oranı \\
\hline AKO & Aktif kârlılık Oranı \\
\hline
\end{tabular}

Kaynak: Yazarlar tarafından hazırlanmıştır.

Hisse Başına Kâr işletmelerin diğer işletmelere kıyasla gücünü tespit etmek ve performansını değerlendirmek için kullanıldığından kriterlerden biri olarak belirlenmiştir. Yatırım kararlarında ve şirket değerlemesinde önemli bir gösterge olan hisse başına kârın yüksek olması şirketin kârlı bir şekilde büyüdüğü şeklinde ifade edilebilir. Likidite oranları içinde yer alan cari oran, işletmelerin kısa vadeli borçlarını karşılama gücünü ifade eder. Oranın 1'den büyük olması beklenmektedir. Nakit oran değişen piyasa şartlarında işletmelerin kısa vadeli borçlarını, likit varlıklarıyla ödeme gücünü ifade etmektedir. Nakit oranın 0.20'nin altına düşmemesi istenmektedir ancak çok yüksek olması da işletmede âtıl durumda fon olduğunu ve efektif kullanamadığını gösterir. Aktif Devir Hızı işletmenin toplam varlıklarını yılda kaç kez döndürdüğünü gösterir. Oranın yüksek olması işletme performansının da yüksek olduğunu ifade eder. Stok Devir Hızı işletmelerin stoklarını yılda kaç kez yenilediğini gösteren önemli bir finansal performans oranıdır. Oranın yüksek olması işletmenin satış başarısını ifade edebilir. Alacak Devir Hızı, işletmelerin alacakların ne sürede tahsil ettiğini ifade eder. Bu oranın yüksek olması işletmenin alacaklarını kısa sürede tahsil ettiğini gösterir. Finansal Kaldıraç Oranı, işletmelerin varlıklarının ne kadarını borçları ile finanse ettiğini gösterir. Oranın düşük olması toplam borçların toplam aktiflere kıyasla daha az olduğunu ve borç ödeme riskinin olmadığını gösterir. Aktif Kârlılık Oranı, işletmelerin varlıklarıyla kâr yaratmada ne ölçüde başarılı olduğunu ifade eder. Bu oranın büyük olması işletmenin kâr elde etmede başarılı olduğu şeklinde söylenebilir.

BIST Gıda, İçecek endeksinde yer alan işletmelerin 11.03.2020 - 31.12.2020 tarihleri arasındaki finansal göstergeleriyle hazırlanan karar değerlerine ilişkin matris Tablo 3' de gösterilmiştir. 
Tablo 3. Endekse İlişkin Karar Matrisi

\begin{tabular}{|c|c|c|c|c|c|c|c|c|}
\hline İşletme/Kriter & HBК & $\mathrm{CO}$ & NO & AkDH & SDH & ADH & FK & AK \\
\hline G1 & 4.1961 & 1.3250 & 67.6125 & 0.5253 & 6.2087 & 7.7799 & 23.6841 & 3.5769 \\
\hline G2 & 3.1943 & 1.0760 & 3.7407 & 0.6934 & 1.8954 & 7.0827 & 34.4647 & 2.9472 \\
\hline G3 & 2.6112 & 0.1910 & 72.1446 & 1.6137 & 9.5910 & 10.2918 & 24.3533 & 2.7007 \\
\hline G4 & 7.2001 & 1.8030 & 104.8048 & 0.7392 & 8.0402 & 10.0974 & 30.7559 & 4.3374 \\
\hline G5 & 3.3796 & 2.8350 & 29.5707 & 0.2683 & 0.7387 & 3.5812 & 0.1232 & 3.4640 \\
\hline G6 & 3.4476 & 3.5190 & 65.7207 & 0.2281 & 0.9841 & 5.1700 & 8.9399 & 3.4151 \\
\hline G7 & 3.7635 & 2.1570 & 91.6213 & 1.4007 & 2.5447 & 21.2525 & 19.6969 & 4.5357 \\
\hline G8 & 3.6068 & 2.1980 & 3.4291 & 0.8304 & 4.4125 & 5.4513 & 9.7357 & 3.8089 \\
\hline G9 & 4.5173 & 1.3080 & 11.2559 & 0.8249 & 3.6562 & 3.6912 & 37.1645 & 4.3411 \\
\hline G10 & 3.5432 & 1.4070 & 1.0596 & 0.8200 & 1.7833 & 2.6262 & 14.9073 & 4.4364 \\
\hline G11 & 3.5022 & 2.7980 & 15.4869 & 1.0147 & 5.8046 & 2.2272 & 6.0763 & 3.8548 \\
\hline G12 & 3.7103 & 0.8610 & 1.0560 & 0.6700 & 3.5000 & 2.4100 & 79.7660 & 4.3554 \\
\hline G13 & 3.6550 & 2.3860 & 59.6609 & 1.0153 & 8.3909 & 3.2717 & 30.4353 & 4.2542 \\
\hline G14 & 3.5959 & 1.4470 & 0.3869 & 0.6691 & 1.9404 & 12.8673 & 12.2568 & 3.1595 \\
\hline G15 & 4.2653 & 1.5190 & 20.8475 & 0.8857 & 9.0384 & 6.0325 & 7.6332 & 4.6597 \\
\hline G16 & 3.5979 & 0.4560 & 4.1538 & 0.6078 & 5.8329 & 4.5764 & 61.5091 & 2.7055 \\
\hline G17 & 3.9034 & 1.1330 & 0.0691 & 1.1639 & 8.3249 & 4.5438 & 14.1111 & 3.9503 \\
\hline G18 & 3.7845 & 2.1480 & 21.0020 & 1.1677 & 3.2930 & 3.3521 & 23.6691 & 4.5396 \\
\hline G19 & 0.0145 & 1.1310 & 1.3500 & 0.5300 & 1.2200 & 4.5400 & 104.0310 & 0.0636 \\
\hline G20 & 4.1167 & 1.3650 & 7.1101 & 0.7683 & 1.9134 & 4.3735 & 45.2053 & 6.5231 \\
\hline G21 & 4.2591 & 1.3220 & 32.7123 & 2.5660 & 11.8231 & 7.4392 & 40.2438 & 4.4993 \\
\hline G22 & 7.6774 & 2.1190 & 104.9610 & 0.6153 & 8.5972 & 3.3701 & 51.2954 & 5.5999 \\
\hline G23 & 7.5761 & 2.6470 & 1.2901 & 0.2350 & 6.1900 & 15.2001 & 11.2500 & 7.8251 \\
\hline
\end{tabular}

Entropi yönteminde karar matrisindeki tüm değerlerin pozitif olması gerekmektedir. Bu sebeple karar matrisindeki bazı kriterlerde sıfır ya da negatif değerler bulunduğundan Z-Skoru dönüşümü ile değerler pozitif hale getirilmiştir. Elde edilen dönüşümlü veriler Tablo 3'te sunulmuştur.

Eşitlik (4)'den faydalanarak karar matrisindeki değerler normalize edilir. Tablo 4'te normalize karar matrisi yer almaktadir.

Tablo 4. Normalize Karar Matrisi

\begin{tabular}{ccccccccc}
\hline İssletme/Kriter & HBK & CO & NO & AkDH & SDH & ADH & FK & AK \\
\hline G1 & 0.0451 & 0.0338 & 0.0938 & 0.0265 & 0.0537 & 0.0514 & 0.0343 & 0.0382 \\
\hline G2 & 0.0343 & 0.0275 & 0.0052 & 0.0349 & 0.0164 & 0.0468 & 0.0499 & 0.0315 \\
\hline G3 & 0.0280 & 0.0049 & 0.1001 & 0.0813 & 0.0829 & 0.0681 & 0.0352 & 0.0289 \\
\hline G4 & 0.0773 & 0.0461 & 0.1454 & 0.0372 & 0.0695 & 0.0668 & 0.0445 & 0.0464 \\
\hline G5 & 0.0363 & 0.0724 & 0.0410 & 0.0135 & 0.0064 & 0.0237 & 0.0002 & 0.0370 \\
\hline G6 & 0.0370 & 0.0899 & 0.0911 & 0.0115 & 0.0085 & 0.0342 & 0.0129 & 0.0365 \\
\hline G7 & 0.0404 & 0.0551 & 0.1271 & 0.0706 & 0.0220 & 0.1405 & 0.0285 & 0.0485 \\
\hline G8 & 0.0387 & 0.0561 & 0.0048 & 0.0418 & 0.0381 & 0.0360 & 0.0141 & 0.0407 \\
\hline G9 & 0.0485 & 0.0334 & 0.0156 & 0.0416 & 0.0316 & 0.0244 & 0.0538 & 0.0464 \\
\hline G10 & 0.0381 & 0.0359 & 0.0015 & 0.0413 & 0.0154 & 0.0174 & 0.0216 & 0.0474 \\
\hline G11 & 0.0376 & 0.0715 & 0.0215 & 0.0511 & 0.0502 & 0.0147 & 0.0088 & 0.0412 \\
\hline G12 & 0.0398 & 0.0220 & 0.0015 & 0.0337 & 0.0302 & 0.0159 & 0.1154 & 0.0466 \\
\hline G13 & 0.0393 & 0.0609 & 0.0827 & 0.0511 & 0.0725 & 0.0216 & 0.0440 & 0.0455 \\
\hline G14 & 0.0386 & 0.0370 & 0.0005 & 0.0337 & 0.0168 & 0.0851 & 0.0177 & 0.0338 \\
\hline G15 & 0.0458 & 0.0388 & 0.0289 & 0.0446 & 0.0781 & 0.0399 & 0.0110 & 0.0498 \\
\hline G16 & 0.0386 & 0.0116 & 0.0058 & 0.0306 & 0.0504 & 0.0303 & 0.0890 & 0.0289 \\
\hline G17 & 0.0419 & 0.0289 & 0.0001 & 0.0586 & 0.0719 & 0.0300 & 0.0204 & 0.0422 \\
\hline G18 & 0.0406 & 0.0549 & 0.0291 & 0.0588 & 0.0285 & 0.0222 & 0.0342 & 0.0485 \\
\hline G19 & 0.0002 & 0.0289 & 0.0019 & 0.0267 & 0.0105 & 0.0300 & 0.1505 & 0.0007 \\
\hline G20 & 0.0442 & 0.0349 & 0.0099 & 0.0387 & 0.0165 & 0.0289 & 0.0654 & 0.0697 \\
\hline G21 & 0.0457 & 0.0338 & 0.0454 & 0.1292 & 0.1022 & 0.0492 & 0.0582 & 0.0481 \\
\hline G22 & 0.0824 & 0.0541 & 0.1456 & 0.0310 & 0.0743 & 0.0223 & 0.0742 & 0.0599 \\
\hline G23 & 0.0814 & 0.0676 & 0.0018 & 0.0118 & 0.0535 & 0.1005 & 0.0163 & 0.0836 \\
\hline & & & & & & & & \\
\hline & & & & & & \\
\hline
\end{tabular}

Eşitlik (5) ve Eşitlik (6)'dan yararlanılarak kriterlerin Entropi değerleri ile farklılaşma değerleri hesaplandıktan sonra Eşitlik (7)'de yer alan hesaplama ile kriter Entropi ağırlıkları elde edilmiştir. Tablo 5 'te kriterlere ilişkin Entropi değerleri ve ağırlıkları yer almaktadır. 
Tablo 5. Entropi Değerleri ve Kriter Ağırlıkları

\begin{tabular}{|c|c|c|c|c|c|c|c|c|}
\hline İşletme/Kriter & HBK & $\mathrm{CO}$ & NO & AkDH & SDH & ADH & FK & AK \\
\hline G1 & -0.1397 & -0.1146 & -0.2219 & -0.0961 & -0.1569 & -0.1526 & -0.1156 & -0.1248 \\
\hline G2 & -0.1157 & -0.0988 & -0.0273 & -0.1172 & -0.0673 & -0.1434 & -0.1495 & -0.1089 \\
\hline G3 & -0.1002 & -0.0260 & -0.2303 & -0.2040 & -0.2064 & -0.1829 & -0.1179 & -0.1023 \\
\hline G4 & -0.1979 & -0.1417 & -0.2803 & -0.1225 & -0.1853 & -0.1807 & -0.1385 & -0.1424 \\
\hline G5 & -0.1204 & -0.1901 & -0.1310 & -0.0582 & -0.0323 & -0.0886 & -0.0015 & -0.1220 \\
\hline G6 & -0.1220 & -0.2165 & -0.2183 & -0.0513 & -0.0405 & -0.1154 & -0.0562 & -0.1208 \\
\hline G7 & -0.1297 & -0.1597 & -0.2621 & -0.1871 & -0.0839 & -0.2758 & -0.1014 & -0.1467 \\
\hline G8 & -0.1259 & -0.1617 & -0.0254 & -0.1328 & -0.1246 & -0.1198 & -0.0600 & -0.1303 \\
\hline G9 & -0.1468 & -0.1136 & -0.0649 & -0.1322 & -0.1092 & -0.0906 & -0.1572 & -0.1425 \\
\hline G10 & -0.1244 & -0.1195 & -0.0096 & -0.1316 & -0.0643 & -0.0704 & -0.0827 & -0.1446 \\
\hline G11 & -0.1234 & -0.1886 & -0.0825 & -0.1520 & -0.1501 & -0.0621 & -0.0416 & -0.1314 \\
\hline G12 & -0.1284 & -0.0839 & -0.0096 & -0.1144 & -0.1058 & -0.0660 & -0.2492 & -0.1428 \\
\hline G13 & -0.1271 & -0.1705 & -0.2062 & -0.1521 & -0.1903 & -0.0829 & -0.1375 & -0.1405 \\
\hline G14 & -0.1257 & -0.1219 & -0.0040 & -0.1143 & -0.0686 & -0.2097 & -0.0715 & -0.1144 \\
\hline G15 & -0.1412 & -0.1261 & -0.1025 & -0.1387 & -0.1991 & -0.1285 & -0.0498 & -0.1494 \\
\hline G16 & -0.1257 & -0.0519 & -0.0297 & -0.1067 & -0.1506 & -0.1059 & -0.2153 & -0.1025 \\
\hline G17 & -0.1330 & -0.1025 & -0.0009 & -0.1663 & -0.1893 & -0.1053 & -0.0794 & -0.1336 \\
\hline G18 & -0.1302 & -0.1593 & -0.1030 & -0.1666 & -0.1013 & -0.0844 & -0.1155 & -0.1468 \\
\hline G19 & -0.0014 & -0.1024 & -0.0118 & -0.0967 & -0.0480 & -0.1052 & -0.2850 & -0.0050 \\
\hline G20 & -0.1379 & -0.1170 & -0.0455 & -0.1258 & -0.0678 & -0.1025 & -0.1783 & -0.1857 \\
\hline G21 & -0.1411 & -0.1144 & -0.1403 & -0.2644 & -0.2331 & -0.1482 & -0.1655 & -0.1459 \\
\hline G22 & -0.2058 & -0.1579 & -0.2805 & -0.1077 & -0.1931 & -0.0848 & -0.1930 & -0.1685 \\
\hline G23 & -0.2041 & -0.1821 & -0.0113 & -0.0525 & -0.1566 & -0.2309 & -0.0670 & -0.2075 \\
\hline Toplam & $-3,0475$ & $-3,0207$ & $-2,4991$ & $-2,9912$ & $-2,9245$ & $-2,9366$ & $-2,8291$ & $-3,0596$ \\
\hline$e_{j}$ & 0.9719 & 0.9634 & 0.7970 & 0.9540 & 0.9327 & 0.9366 & 0.9023 & 0.9758 \\
\hline$d_{j}$ & 0.0281 & 0.0366 & 0.2030 & 0.0460 & 0.0673 & 0.0634 & 0.0977 & 0.0242 \\
\hline$w_{j}$ & 0.0495 & 0.0647 & 0.3584 & 0.0813 & 0.1189 & 0.1120 & 0.1725 & 0.0427 \\
\hline
\end{tabular}

Tablo 5 'te verilen kriter ağırlıklarına $\left(w_{j}\right)$ bakıldığında en önemli finansal performans göstergesinin Nakit Oran (0.3584) olduğu, en az önemli göstergenin ise Aktif, Kârlılık Oranı (0.0427) olduğu görülmektedir. Entropi yöntemi ile kriter ağırlıkları hesaplandıktan sonra işletmelerin finansal performanslarının sıralanması amacıyla MAIRCA yöntemi kullanılmıştır. Bu aşamada ilk olarak Eşitlik (9)'da bulunan formül ile karar alternatiflerinin öncelik değerleri $\left(P_{A i}\right)$ hesaplanmıştır. Alternatiflerin öncelik değerleri hesaplandıktan sonra, teorik derecelendirme matrisini $\left(T_{p}\right)$ oluşturmak için Eşitlik (11)'den faydalanılmıştır. Bulunan değerler Tablo 6'da gösterilmiştir.

Tablo 6. Teorik Derecelendirme Matrisi $\left(T_{p}\right)$

\begin{tabular}{lll}
\hline Kriterler & $\boldsymbol{T}_{\boldsymbol{p}}$ & $\boldsymbol{P}_{\boldsymbol{A} \boldsymbol{i}}$ \\
\hline HBK & 0.0022 & 0.0028 \\
\hline CO & 0.0028 & 0.0028 \\
\hline NO & 0.0156 & 0.0028 \\
\hline AkDH & 0.0035 & 0.0028 \\
\hline SDH & 0.0052 & 0.0028 \\
\hline ADH & 0.0049 & 0.0028 \\
\hline FK & 0.0075 & 0.0028 \\
\hline AK & 0.0019 & 0.0028
\end{tabular}

Eşitlik (13) ve (14)'den faydalanılarak teorik derecelendirme matrisi normalize edilerek gerçek derecelendirme matrisi elde edilmiştir. Tablo $7^{\prime}$ de gerçek derecelendirme matrisi gösterilmektedir. 
Tablo 7. Gerçek Derecelendirme Matrisi

\begin{tabular}{ccccccccc}
\hline Isşetme/Kriter & HBK & CO & NO & AkDH & SDH & ADH & FK & AK \\
\hline G1 & 0.0012 & 0.0010 & 0.0100 & 0.0004 & 0.0026 & 0.0014 & 0.0058 & 0.0008 \\
\hline G2 & 0.0009 & 0.0007 & 0.0005 & 0.0007 & 0.0046 & 0.0012 & 0.0050 & 0.0007 \\
\hline G3 & 0.0007 & 0.0000 & 0.0107 & 0.0021 & 0.0010 & 0.0021 & 0.0058 & 0.0006 \\
\hline G4 & 0.0020 & 0.0014 & 0.0156 & 0.0008 & 0.0018 & 0.0020 & 0.0053 & 0.0010 \\
\hline G5 & 0.0009 & 0.0022 & 0.0044 & 0.0001 & 0.0052 & 0.0003 & 0.0075 & 0.0008 \\
\hline G6 & 0.0010 & 0.0028 & 0.0098 & 0.0000 & 0.0051 & 0.0008 & 0.0069 & 0.0008 \\
\hline G7 & 0.0011 & 0.0017 & 0.0136 & 0.0018 & 0.0043 & 0.0049 & 0.0061 & 0.0011 \\
\hline G8 & 0.0010 & 0.0017 & 0.0005 & 0.0009 & 0.0035 & 0.0008 & 0.0068 & 0.0009 \\
\hline G9 & 0.0013 & 0.0009 & 0.0017 & 0.0009 & 0.0038 & 0.0004 & 0.0048 & 0.0010 \\
\hline G10 & 0.0010 & 0.0010 & 0.0001 & 0.0009 & 0.0047 & 0.0001 & 0.0064 & 0.0010 \\
\hline G11 & 0.0010 & 0.0022 & 0.0023 & 0.0012 & 0.0028 & 0.0000 & 0.0071 & 0.0009 \\
\hline G12 & 0.0010 & 0.0006 & 0.0001 & 0.0007 & 0.0039 & 0.0000 & 0.0018 & 0.0010 \\
\hline G13 & 0.0010 & 0.0019 & 0.0089 & 0.0012 & 0.0016 & 0.0003 & 0.0053 & 0.0010 \\
\hline G14 & 0.0010 & 0.0011 & 0.0000 & 0.0007 & 0.0046 & 0.0027 & 0.0066 & 0.0007 \\
\hline G15 & 0.0012 & 0.0011 & 0.0031 & 0.0010 & 0.0013 & 0.0010 & 0.0070 & 0.0011 \\
\hline G16 & 0.0010 & 0.0002 & 0.0006 & 0.0006 & 0.0028 & 0.0006 & 0.0031 & 0.0006 \\
\hline G17 & 0.0011 & 0.0008 & 0.0000 & 0.0014 & 0.0016 & 0.0006 & 0.0065 & 0.0009 \\
\hline G18 & 0.0011 & 0.0017 & 0.0031 & 0.0014 & 0.0040 & 0.0003 & 0.0058 & 0.0011 \\
\hline G19 & 0.0000 & 0.0008 & 0.0002 & 0.0005 & 0.0049 & 0.0006 & 0.0000 & 0.0000 \\
\hline G20 & 0.0012 & 0.0010 & 0.0010 & 0.0008 & 0.0046 & 0.0005 & 0.0042 & 0.0015 \\
\hline G21 & 0.0012 & 0.0010 & 0.0048 & 0.0035 & 0.0000 & 0.0013 & 0.0046 & 0.0011 \\
\hline G22 & 0.0022 & 0.0016 & 0.0156 & 0.0006 & 0.0015 & 0.0003 & 0.0038 & 0.0013 \\
\hline G23 & 0.0021 & 0.0021 & 0.0002 & 0.0000 & 0.0026 & 0.0033 & 0.0067 & 0.0019 \\
\hline & & & & & & & &
\end{tabular}

Eşitlik 16'dan faydalanılarak teorik derece değerleri ile gerçek derece değerleri arasında farkın alınmasıyla boşluk matrisi $(G)$ hesaplanır. Tablo 8' de boşluk matrisi verilmiştir.

Tablo 8. Boşluk Matrisi

\begin{tabular}{ccccccccc}
\hline İşletme/Kriter & HBK & CO & NO & AkDH & SDH & ADH & FK & AK \\
\hline G1 & 0.0010 & 0.0019 & 0.0055 & 0.0031 & 0.0026 & 0.0034 & 0.0017 & 0.0010 \\
\hline G2 & 0.0013 & 0.0021 & 0.0150 & 0.0028 & 0.0005 & 0.0036 & 0.0025 & 0.0012 \\
\hline G3 & 0.0014 & 0.0028 & 0.0049 & 0.0014 & 0.0041 & 0.0028 & 0.0017 & 0.0012 \\
\hline G4 & 0.0001 & 0.0014 & 0.0001 & 0.0028 & 0.0034 & 0.0029 & 0.0022 & 0.0008 \\
\hline G5 & 0.0012 & 0.0006 & 0.0112 & 0.0035 & $\mathbf{0 . 0 0 0 0}$ & 0.0045 & $\mathbf{0 . 0 0 0 0}$ & 0.0010 \\
\hline G6 & 0.0012 & $\mathbf{0 . 0 0 0 0}$ & 0.0058 & 0.0035 & 0.0001 & 0.0041 & 0.0006 & 0.0011 \\
\hline G7 & 0.0011 & 0.0012 & 0.0020 & 0.0018 & 0.0008 & $\mathbf{0 . 0 0 0 0}$ & 0.0014 & 0.0008 \\
\hline G8 & 0.0011 & 0.0011 & 0.0151 & 0.0026 & 0.0017 & 0.0040 & 0.0007 & 0.0010 \\
\hline G9 & 0.0009 & 0.0019 & 0.0139 & 0.0026 & 0.0014 & 0.0045 & 0.0027 & 0.0008 \\
\hline G10 & 0.0012 & 0.0018 & 0.0154 & 0.0026 & 0.0005 & 0.0048 & 0.0011 & 0.0008 \\
\hline G11 & 0.0012 & 0.0006 & 0.0133 & 0.0023 & 0.0024 & 0.0049 & 0.0004 & 0.0010 \\
\hline G12 & 0.0011 & 0.0022 & 0.0154 & 0.0029 & 0.0013 & 0.0048 & 0.0057 & 0.0008 \\
\hline G13 & 0.0011 & 0.0010 & 0.0067 & 0.0023 & 0.0036 & 0.0046 & 0.0022 & 0.0009 \\
\hline G14 & 0.0011 & 0.0018 & 0.0155 & 0.0029 & 0.0006 & 0.0021 & 0.0009 & 0.0011 \\
\hline G15 & 0.0010 & 0.0017 & 0.0125 & 0.0025 & 0.0039 & 0.0039 & 0.0005 & 0.0008 \\
\hline G16 & 0.0011 & 0.0026 & 0.0150 & 0.0030 & 0.0024 & 0.0043 & 0.0044 & 0.0012 \\
\hline G17 & 0.0011 & 0.0020 & 0.0156 & 0.0021 & 0.0035 & 0.0043 & 0.0010 & 0.0009 \\
\hline G18 & 0.0011 & 0.0012 & 0.0125 & 0.0021 & 0.0012 & 0.0046 & 0.0017 & 0.0008 \\
\hline G19 & 0.0022 & 0.0020 & 0.0154 & 0.0031 & 0.0002 & 0.0043 & 0.0075 & 0.0019 \\
\hline G20 & 0.0010 & 0.0018 & 0.0145 & 0.0027 & 0.0005 & 0.0043 & 0.0033 & 0.0003 \\
\hline G21 & 0.0010 & 0.0019 & 0.0107 & $\mathbf{0 . 0 0 0 0}$ & 0.0052 & 0.0035 & 0.0029 & 0.0008 \\
\hline G22 & $\mathbf{0 . 0 0 0 0}$ & 0.0012 & $\mathbf{0 . 0 0 0 0}$ & 0.0029 & 0.0037 & 0.0046 & 0.0037 & 0.0005 \\
\hline G23 & 0.0001 & 0.0007 & 0.0154 & 0.0035 & 0.0025 & 0.0015 & 0.0008 & $\mathbf{0 . 0 0 0 0}$ \\
\hline & & & & & & & &
\end{tabular}

Tablo 8 incelendiğinde Hisse Başına Kâr Oranı ve Nakit Oranı kriterinde G22 (ULKER), Cari Oran kriterinde G6 (FADE), Aktif Devir Hızı kriterinde G21 (ULUUN), Stok Devir Hızı Oranı ve Finansal Kaldıraç Oranı kriterlerinde G5 (ERSU), Alacak Devir Hızı kriterinde G7 (FRIGO), Aktif Kârlılık Oranı kriterinde G23 (VANGD) alternatiflerinin en iyi olduğu tespit edilmiştir. 
Boşluk matrisi hesaplandıktan sonra Eşitlik (17)'deki formül kullanılarak her bir alternatif için nihai kriter fonksiyon değerleri $\left(Q_{i}\right)$ bulunmuştur. Tablo $9^{\prime}$ da nihai kriter fonksiyon değerleri ve alternatif sıralamaları gösterilmiştir.

Tablo 9. Nihai Kriter Fonksiyon Değerleri ve Alternatif Sıralamaları

\begin{tabular}{ccc|ccc}
\hline Kod & $\boldsymbol{Q}_{\boldsymbol{i}}$ & Siralama & Kod & $\boldsymbol{Q}_{\boldsymbol{i}}$ & Siralama \\
\hline G7 & 0.0090 & 1 & G11 & 0.0260 & 13 \\
\hline G4 & 0.0137 & 2 & G15 & 0.0267 & 14 \\
\hline G6 & 0.0165 & 3 & G8 & 0.0274 & 15 \\
\hline G22 & 0.0166 & 4 & G10 & 0.0282 & 16 \\
\hline G1 & 0.0202 & 5 & G20 & 0.0285 & 17 \\
\hline G3 & 0.0205 & 6 & G9 & 0.0287 & 18 \\
\hline G5 & 0.0220 & 7 & G2 & 0.0290 & 19 \\
\hline G13 & 0.0224 & 8 & G17 & 0.0305 & 20 \\
\hline G23 & 0.0246 & 9 & G16 & 0.0340 & 21 \\
\hline G18 & 0.0251 & 10 & G12 & 0.0344 & 22 \\
\hline G21 & 0.0259 & 11 & G19 & 0.0365 & 23 \\
\hline G14 & 0.0260 & 12 & & & \\
\hline
\end{tabular}

Tablo 9 incelendiğinde $Q_{i}$ değerlerine göre en iyi alternatifin G7 (FRIGO), en kötü alternatifin ise G19 (TKURU) olduğu görülmektedir.

\section{Sonuç}

Çalışmada BIST Gıda, İçecek endeksinde bulunan işletmelerin COVID-19 pandemisi sürecindeki finansal performansları Entropi ve MAIRCA yöntemleri ile analiz edilmiştir. Karar probleminde bulunan kriter ağırlıklandırma hesaplamasında kullanılan Entropi yöntemine göre çalışmada yer alan finansal kriterlerden Nakit Oranın $\left(w_{j}=0.3584\right)$ alternatifler için en önemli kriter olduğu tespit edilmiştir. En önemli kriterin nakit oranı çıkması tüketicilerin pandemi sürecinde artan temel gıda harcamalarına bağlı olarak işletmelere nakit girişinin artmasının doğal bir sonucu olduğu varsayılabilir. Daha sonra kriterler önem derecelerine göre Finansal Kaldıraç Oranı $\left(w_{j}=0.1725\right)$, Stok Devir Hızı Oranı $\left(w_{j}=0.1189\right)$, Alacak Devir Hızı Oranı $\left(w_{j}=0.1120\right)$, Aktif Devir Hizı Oranı $\left(w_{j}=0.0813\right)$, Cari Oran $\left(w_{j}=\right.$ 0.0647), Hisse Başına Kâr Oranı $\left(w_{j}=0.0495\right)$ ve Aktif Kârlılık Oranı $\left(w_{j}=0.0427\right)$ şeklinde sıralanmıştır. Entropi metoduyla kriter ağırlıkları bulunduktan sonra, MAIRCA metoduyla alternatifler finansal performans olarak sıralanmıştır. Buna göre COVID-19 pandemisi sürecinde en iyi finansal performans gösteren işletmeler ilk üç sırayla $Q_{i}=0.0090$ nihai kriter fonksiyon değeri ile G7 (FRIGO), $Q_{i}=0.0137$ nihai kriter fonksiyon değeri ile G4 (CCOLA) ve $Q_{i}=0.0165$ nihai kriter fonksiyon değeri ile G6 (FADE), son üç ise sırayla $Q_{i}=0.0340$ nihai kriter fonksiyon değeri ile G16 (PINSU), $Q_{i}=0.0344$ nihai kriter fonksiyon değeri ile G12 (MERKO) ve $Q_{i}=0.0365$ nihai kriter fonksiyon değeri ile G19 (TKURU) olarak tespit edilmiştir.

Entropi ve MAIRCA yöntemi çok kriterli karar verme problemlerinde birlikte, farklı kriter ve süreler için rahatlıklar kullanılabilir. Çalışmada COVID-19 pandemisi süreci ele alınmış olsa da gelecek çalışmalarda pandemi öncesi ve sonrası olarak ele alınarak kriterlerin ne yönde farklılaştığı ve alternatiflerin nasıl değiştiği tespit edilebilir. Ayrıca bu çalışmada kullanılan yöntemlerden farklı olarak literatürde birçok performans değerlendirme analizi kullanılabilmektedir. Gelecek çalışmalarda gıda endeksinde ve BIST'de yer alan diğer endekslerde farklı metotlar ve dönemlerle ele alınarak incelenebilir.

\section{Hakem Değerlendirmesi / Peer-review:}

Dış, bağımsız

Externally peer-reviewed

\section{Çıkar Çatışması / Conflict of interests:}

Yazar(lar) çıkar çatışması bildirmemiştir.

The author(s) has (have) no conflict of interest to declare. 


\section{Finansal Destek/Grant Support:}

Yazar bu çalışma için finansal destek almadığını beyan etmiştir.

The author declared that this study has received no financial support

\section{Teşekkür / Acknowledgement:}

Çalışmada yararlanılan kaynaklara ulaşılmasında veri tabanından yararlandığımız Osmaniye Korkut Ata Üniversitesi'ne teşekkür ederiz.

We would like to thank Osmaniye Korkut Ata University, whose database we used to access the sources used in the study.

\section{Kaynakça / References}

Anthony, P., Behnoee, B., Hassanpour, M. \& Pamucar, D. (2019). Financial Performance Evaluation of Seven Indian Chemical Companies. Decision Making: Application in Management and Engineering, 2(2), 81-99.

Ayçin, E. \& Güçlü, P. (2020). BIST Ticaret Endeksinde Yer Alan İşletmelerin Finansal Performanslarının Entropi ve MAIRCA Yöntemleri ile Değerlendirilmesi. Muhasebe ve Finansman Dergisi, (85), 287-312.

Ayçin, E. (2018). BIST Menkul Kıymet Yatırım Ortaklıkları Endeksinde (XYORT) Yer Alan İşletmelerin Finansal Performanslarının Entropi ve Gri İlişkisel Analiz Bütünleşik Yaklaşımı ile Değerlendirilmesi. Dokuz Eylül Üniversitesi İktisadi ve İdari Bilimler Fakültesi Dergisi, 33(2), 595-622

Bayrakdaroğlu, A. \& Yalçın, N. (2012). Strategic Financial Performance Evaluation of the Turkish Companies Traded on ISE. Ege Akademik Bakış Dergisi, 12(4), 529-539.

Çalış, N. \& Sakarya, Ş. (2020). Finansal Performans ve Hisse Senedi Getirisi İlişkisi: BİST Bankacıllk Endeksi Üzerine Bir İnceleme. MANAS Sosyal Araştırmalar Dergisi, 9 (2), 1046-1058

Çanakçıŏlu, M. (2019). BIST Kimya, Petrol, Kauçuk ve Plastik Ürünler Sektöründeki İşletmelerin Finansal Performanslarının Hibrid ÇKKV Yaklaşımı Çerçevesinde Değerlendirilmesi. Beykoz Akademi Dergisi, 7(1), 123-152.

Ersoy, N. (2020). Finansal Performansın Gri İlişkisel Analiz Yöntemi ile Değerlendirilmesi: Borsa İstanbul Ulaştırma Endeksi'ndeki Şirketler Üzerine Bir Araştırma. MUFAD Journal, 86, 223-246.

Ertuğrul, İ. \& Karakaşoğlu, N. (2009). Performance Evaluation of Turkish Cement Firms with Fuzzy Analytic Hierarchy Process and TOPSIS Methods. Expert Systems with Applications, 36(1), 702-715.

Feng, C. M. \& Wang, R. T. (2000). Performance Evaluation for Airlines Including the Consideration of Financial Ratios. Journal of Air Transport Management, 6, 133-142.

Gigović, L., Pamučar, D., Bajić, Z. \& Milićević, M. (2016). The Combination of Expert Judgment and GISMAIRCA Analysis for the Selection of Sites for Ammunition Depots. Sustainability, 8(4), 1-30.

Ho, C. T. \& Wu, Y. S. (2006). Benchmarking Performance Indicators for Banks. Benchmarking: An International Journal, 13(1/2), 147-159.

Işık, Ö. (2019). ENTROPI ve TOPSİS Yöntemleriyle Finansal Performans ile Pay Senedi Getirileri Arasındaki İlişkinin İncelenmesi. Kent Akademisi, 12(1), 200-213.

Lee, P. T. W., Lin, C. W. \& Shin, S. H. (2012). A Comparative Study on Financial Positions of Shipping Companies in Taiwan and Korea using Entropy and Grey Relation Analysis. Expert Systems with Applications, 39(5), 5649-5657.

Li, X., Wang, K., Liu, L., Xin, J., Yang, H. \& Gao, C. (2011). Application of The Entropy Weight and TOPSIS Method in Safety Evaluation of Coal Mines. Procedia Engineering, 26, 2085-2091. 
Orçun, Ç. (2019). Enerji Sektöründe WASPAS Yöntemiyle Performans Analizi. Bolu Abant İzzet Baysal Üniversitesi Sosyal Bilimler Enstitüsü Dergisi, 19(2), 439-453.

Ömürbek, N., Karaatlı, M. \& Balcı, H. F. (2016). Entropi Temelli MAUT ve SAW Yöntemleri ile Otomotiv Firmalarını Performans Değerlemesi. Dokuz Eylül Üniversitesi İktisadi ve İdari Bilimler Fakültesi Dergisi, 31(1), 227- 255.

Pamucar, D. S., Tarle, S. P. \& Parezanovic, T. (2018). New Hybrid Multi- Criteria Decision-Making DEMATEL-MAIRCA Model: Sustainable Selection of a Location for the Development of Multimodal Logistics Centre. Economic Research- Ekonomska istraživanja, 31(1), 1641-1665.

Şahin, A. \& Sarı, E. B. (2019). Entropi Tabanlı TOPSIS ve VIKOR Yöntemleriyle BIST-İmalat İşletmelerinin Finansal ve Borsa Performanslarının Karşılaştırılması. Muhasebe ve Vergi Uygulamaları Dergisi, 12(2), 255-270.

Tetik, N. \& Şahin, A. (2020). Katılım Bankalarının Finansal Performans Analizi. Atatürk Üniversitesi İktisadi ve İdari Bilimler Dergisi, 34, 293-314.

Tseng, F. M., Chiu, Y. J. \& Chen, J. S. (2009). Measuring Business Performance in the High-Tech Manufacturing Industry: A Case Study of Taiwan's Large-Sized TFT-LCD Panel Companies. Omega, 37, 686-697.

Ulutaş, A. (2018). Entropi Tabanlı EDAS Yöntemi ile Lojistik Firmalarının Performans Analizi. Uluslararast İktisadi ve İdari İncelemeler Dergisi, (23), 53-66.

Wang, T. C. \& Lee, H. D. (2009). Developing a Fuzzy TOPSIS Approach Based on Subjective Weights and Objective Weights. Expert Systems with Applications, 6(5), 8980-8985.

Yurdakul, M. \& İç, Y. (2003). Türk Otomotiv Firmalarının Performans Ölçümü ve Analizine Yönelik TOPSIS Yöntemini Kullanan Bir Örnek Çalışma. Gazi Üniversitesi Mühendislik-Mimarlık Fakültesi Dergisi, 18(1), 1-18. 